\title{
MICROANATOMICAL STUDY OF AGE CHANGES IN TUNICA MEDIA OF ASCENDING AORTA
}

\author{
Reba Babu Alex ${ }^{1}$ Lathikumari Kalyani Kutty Amma²
}

${ }^{1}$ Assistant Professor, Department of Anatomy, SUT Academy of Medical Sciences, Vattappara, Trivandrum. ${ }^{2}$ Additional Professor, Department of Anatomy, Government Medical College, Trivandrum.

ABSTRACT
BACKGROUND
Arteriosclerosis, the generalised age related stiffening of conduit arteries affecting mainly the tunica media, is the major risk factor
behind essential hypertension and its sequel.
The aim of this study is to identify the age at which the sclerotic changes begin and to determine the variations in thickness of
tunica media, grades of elastic fragmentation, proportion of collagen fibres and density of smooth muscle cells in it across different
ages.

\section{MATERIALS AND METHODS}

Human ascending aorta specimens from fifty three individuals of different age groups and two foetuses were taken for the study. The tissue samples obtained were subjected to routine histological processing and haematoxylin and eosin staining. Special staining methods were employed to highlight connective tissue and smooth muscles. Thickness of tunica media was measured under 10X objective with an eye piece micrometer. Degree of elastic fragmentation was graded from 1 to 4 according to the severity of the process when examined at a magnification of 40X. A net micrometer was used for counting smooth muscles.

\section{RESULTS}

Tunica media occupied greatest proportion of vessel wall in all ages and it occupied maximum proportion (72.4\%) in the 4 th decade. Long and parallel elastic fibres in tunica media were found to undergo progressive grades of fragmentation with advancing age. Grade 3 and Grade 4 elastic fragmentation were seen after fifth decade. Collagen occupied the interval between fragmented elastic fibres. There was a progressive decrease in the number of smooth muscle cells with age. The average number of smooth muscle cells per $100 \mathrm{~mm}$ square was 113.5 in the foetal group, whereas it was just 7.8 in the 71 - 80 years' age group.

\section{CONCLUSION}

Elastic fragmentation, atrophy of smooth muscle cells and increase in collagen are the factors leading to increased stiffness in conduit arteries and these changes become more prominent after 50 years.

\section{KEYWORDS}

Arteriosclerosis, Essential Hypertension, Ascending Aorta, Tunica Media, Elastic Fragmentation, Smooth Muscle Atrophy.

HOW TO CITE THIS ARTICLE: Alex RB, Amma LKK. Microanatomical study of age changes in tunica media of ascending aorta. J. Evolution Med. Dent. Sci. 2016;5(101):7409-7412, DOI: 10.14260/Jemds/2016/1677

\section{BACKGROUND}

The age changes in systems, organs and tissues are those which occur during the period of decline of life. At present, there are several theories for age related changes in different organs and tissues. Some of which are gene mutation theory, collagen deposit theory, wear and tear theory and autoimmune theory.(1) Arteriosclerosis, the generalised age related stiffening of vessels confined primarily to the media of the conduit arteries appears to be an inevitable process. As the conduit arteries age, changes occur in their composition and structure. These changes lead inexorably to an increase in stiffness of their walls resulting in raised systolic and pulse pressure and greater mechanical load on left ventricle and thus the systemic circulation as a whole. Consequently, there occurs an increase in the risk of stroke, myocardial infarction, renal failure and other sequelae of essential hypertension.(2)

Financial or Other, Competing Interest: None.

Submission 12-11-2016, Peer Review 03-12-2016,

Acceptance 12-12-2016, Published 19-12-2016.

Corresponding Author:

Dr. Reba Babu Alex,

C-29, Aswathy, Pillaveedu Lane,

Kesavadasapuram,

Trivandrum.

E-mail:drrebajohn@yahoo.com

DOI: $10.14260 /$ jemds $/ 2016 / 1677$
The incidence of systolic hypertension in those aged more than 65 years is nearly $65 \%$.(3) The predictive and diagnostic power of changes in arterial stiffness for determining cardiovascular morbidity and mortality is now widely recognised and this predictive ability although effective in the young itself increases with age. Peripheral vascular resistance is the main determinant and a better predictor of cardiovascular risk in subjects younger than 50 years, but large artery stiffness is more important in older subjects. A pharmacological approach to limit or reverse increase in large artery stiffness now forms the basis of novel treatments for cardiovascular disease. (4)

Although, the association between increased arterial stiffness and cardiovascular disease is now well established, the structural changes in the vessel leading to arteriosclerosis remain a subject of debate. The aim of this study is to describe the structural changes in tunica media that lead to arterial stiffness.

\section{MATERIALS AND METHODS}

A case series study was conducted on 55 human ascending aortas, which were collected from autopsies conducted in the mortuary of the Department of Forensic Medicine, Government Medical College, Thiruvananthapuram, during 2012 - 2013. Foetal specimens were also included in the 
present study, which were obtained from foetal autopsies done in the Department of Pathology, Government Medical College, Thiruvananthapuram.

The most frequent causes of death were accidents, suicides and intrauterine death due to non-cardiopulmonary causes in case of foetus. Specimens from autopsies conducted within 6 hours of death were only included to avoid autolytic changes. Cases with post-mortem evidence of significant chronic cardiopulmonary disease like presence of atheromatous plaques in the vessel wall, crush injuries of chest, death due to burns and foetus with congenital cardiac anomalies were excluded.

While conducting autopsy, ascending aorta was located and rectangular tissue samples were collected from their anterior walls, approximately 2 centimetres distal to aortic valve for uniformity. Dissected out specimens were immediately transferred to the fixative solution, $10 \%$ formalin. After 24 hours of fixation, the specimens were subjected to routine histological processing(5) that included dehydration, clearing, impregnation and paraffin embedding. The paraffin blocks thus obtained were serially sectioned at a thickness of 6 microns using a rotary microtome. The sections after incubation for 1 hour were subjected to routine haematoxylin and eosin staining.(5)

To highlight the characteristic features of connective tissue and smooth muscle cells in the vessel wall following special staining methods were employed.

a) Orcein Van Gieson's staining method to observe elastic fibres and collagen fibres, in which elastic fibres appear brown, collagen red and smooth muscle cells yellow.

b) Masson's trichrome to visualise collagen fibres and smooth muscle cells. Collagen appears blue and muscle red.

Mounted sections were observed under low power and high power of binocular microscope with built-in light. Following parameters were observed; elastic fragmentation, number of smooth muscle cells and proportion of collagen fibres.

The specimens were grouped into age intervals of 10 years. Thickness of tunica media was measured under $\mathrm{x} 10$ objective with an eyepiece micrometer. The eyepiece micrometer was calibrated with a stage micrometer. A stage micrometer is a glass slide of 3 inches in length with a scale engraved on it. The scale is $1 \mathrm{~mm}$ long and is divided into 0.1 and 0.01 parts of a millimetre. Value of one eye piece division is determined by calibrating it with the stage micrometer.(6)

Average value of the thickness of media in different fields was determined. The media was defined as 'that part of the vessel wall between internal elastic lamina and external limit of muscle layer. Full wall thickness was also determined. Percentage thickness of tunica media with respect to full wall thickness was calculated. The tunica media of arterial wall was evaluated on the basis of presence and degree of elastic fragmentation and number of smooth muscle cells per 100 $\mathrm{mm}^{2}$ at a magnification of $\mathrm{x} 40$. Elastic fragmentation was defined as focal breakup of elastic fibre in the media of aorta. Degree of elastic fragmentation was graded from 1 to 4 according to the severity of the process when examined at a magnification of $\mathrm{x} 40$ times. The grades were determined by noting various fields. Grades were assigned according to the area showing maximum fragmentation. The criteria for grading were modified from Schlatman and Becker.(7)
Grade 1 - Fewer than 2 foci of elastic fragmentation in one microscopic field.

Grade 2 - More than 2 but less than 10 foci with elastic lamellae fragmentation in one microscopic field.

Grade 3 - More than 10 foci with elastic lamellae fragmentation in one microscopic field.

Grade 4 - Areas comprising between one-third or one-half of medial thickness were fragmented; with loss of parallelism of lamellar components associated with focal orientation changes of muscle cells. Normally, smooth muscle cells are seen circularly arranged in between elastic lamellae.

Number of smooth muscle cells was determined under high power lens ( $\mathrm{x} 40$ objective and $\mathrm{x} 10$ eye piece). A net micrometer with $10 \times 10 \mathrm{~mm}$ square grid composed of 100 squares of $1 \mathrm{~mm}$ size was used for counting. The cells in each $1 \mathrm{~mm}$ square were counted and recorded until the area of 100 squares was evaluated; 5 such different areas were randomly selected and the average number of smooth muscle cells per $100 \mathrm{~mm} 2$ area was calculated.

\section{RESULTS}

The specimens obtained were categorised into various age intervals as given in Table 1 .

\begin{tabular}{|c|c|}
\hline $\begin{array}{c}\text { Age Groups } \\
\text { Foetus }\end{array}$ & No. of Specimens \\
$0-10$ & 2 \\
$10-20$ & 2 \\
$21-30$ & 4 \\
$31-40$ & 8 \\
$41-50$ & 6 \\
$51-60$ & 7 \\
$61-70$ & 9 \\
$71-80$ & 11 \\
\multicolumn{2}{|c|}{ Table 1. Age Distribution } \\
\hline
\end{tabular}

It was observed that percentage thickness of tunica media was greatest in the fourth decade $(72.4 \pm 2.2 \%)$ and after 40 years of age there was a slight reduction in the thickness of tunica media with respect to the full wall.

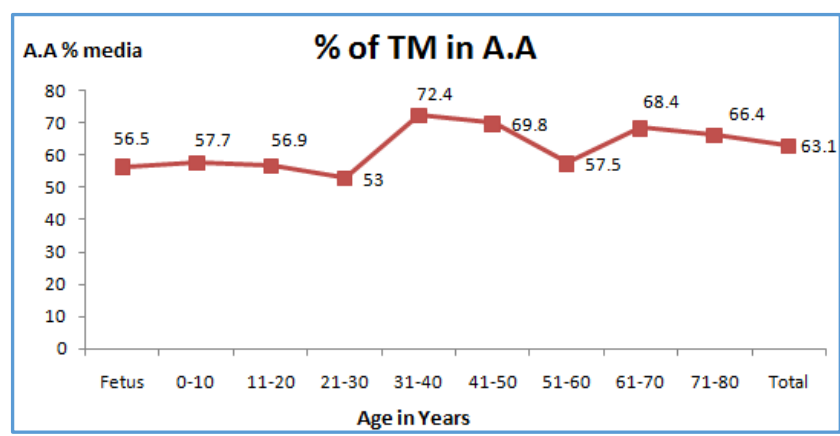

\section{Graph 1. Age Wise Distribution of Mean Percentage Thickness of Tunica Media in Ascending Aorta. AA: Ascending Aorta, TM: Tunica Media}

Till 20 years, elastic laminas in tunica media were long and parallel to each other and of uniform thickness. They were arranged compactly and between elastic lamina were circularly arranged smooth muscle cells surrounded by collagen tissue.

Number of elastic lamina was found to increase up to 20 years. Thereafter, it almost remained same till 50 years. 
Grade 2 elastic fragmentation was noticed from 20 years up to 50 years. Grade 3 fragmentation was seen after 50 years.

In 51 - 60 years' age group, out of 9 tissues 5 showed Grade 3 and 4 showed Grade 2 fragmentation. In 61 - 70 years' group out of 11,10 showed Grade 3 and 1 showed Grade 4 fragmentation. In 71 - 80 age group out of 6, 2 showed Grade 4 and 4 showed Grade 3 fragmentation.

\section{Smooth Muscle Cells}

Maximum number of smooth muscle cells per $100 \mathrm{~mm}^{2}$ of tunica media of ascending aorta was found in the foetal group, which was 113.5 (Graph 2). As the grades of elastic fragmentation increased, especially after 50 years, the smooth cells came to be oriented in different directions and there was degeneration of the smooth muscle cells (Fig 3, Graph 2). Thus, the average number of smooth muscle cells was found to decrease with increase in age (Graph 2).

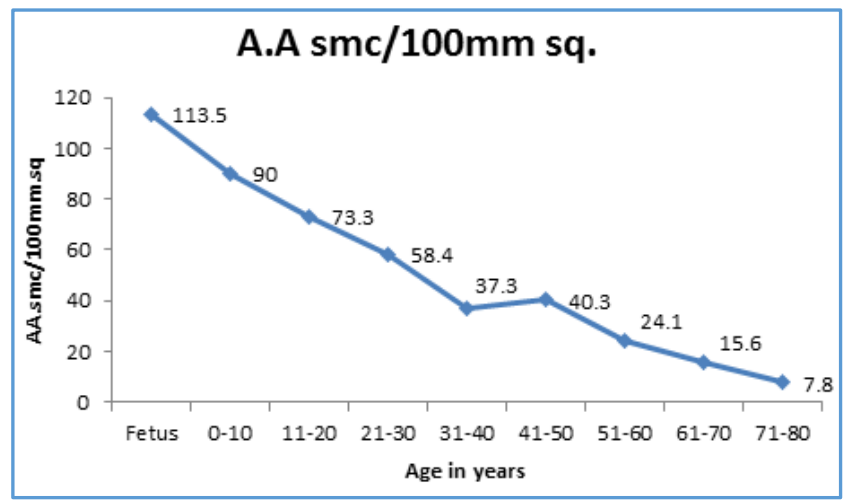

Graph 2. Average Number of Smooth Muscle Cells across Different Age Groups in Ascending Aorta. AA: Ascending Aorta, SMC: Smooth Muscle Cells

\section{Collagen Fibres}

With Masson's trichrome stain, collagen fibres were seen surrounding smooth muscle cells. With increase in elastic fragmentation and changes in orientation of smooth muscle cells, collagen occupied the space between fragmented elastic fibres. However, quantitative measurement of collagen fibres could not be made.

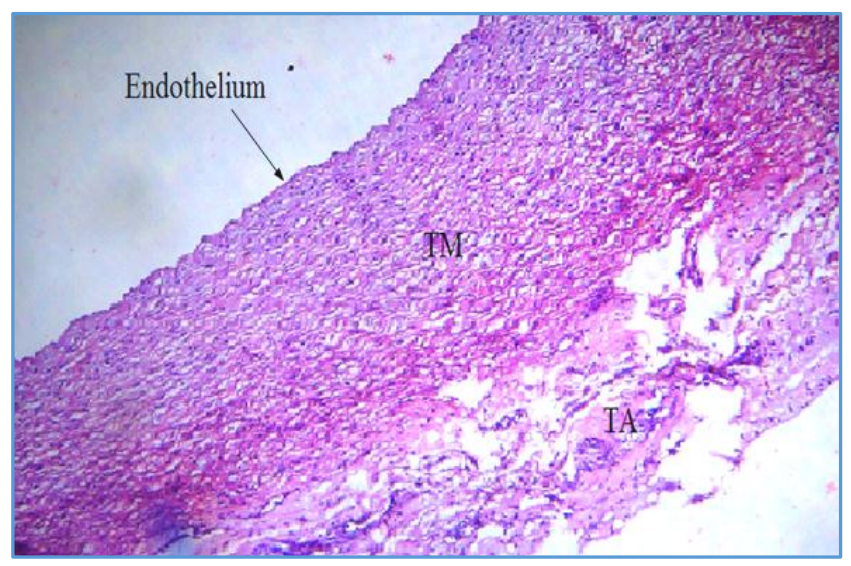

Figure 1. Ascending Aorta of a Foetus of 34 Weeks showing Compactly Arranged Elastic Fibres which are Parallel to Each Other in the Tunica Media (TM). Nuclei of Smooth Muscle Cells are seen in between Elastic Lamellae. No SubEndothelial Layer is seen in Tunica Intima (TI). (H \& E Staining $\times 100)$

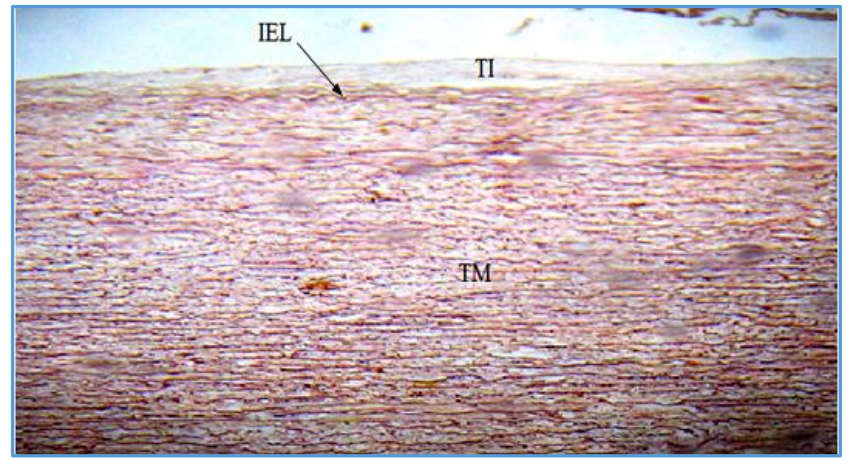

Figure 2. Ascending Aorta of 62-Year-Old Male showing Replication of Internal Elastic Lamina (IEL) and Grade 3 Fragmentation in Tunica Media. (Orcein × 100). TI: Tunica Intima, TM: Tunica Media

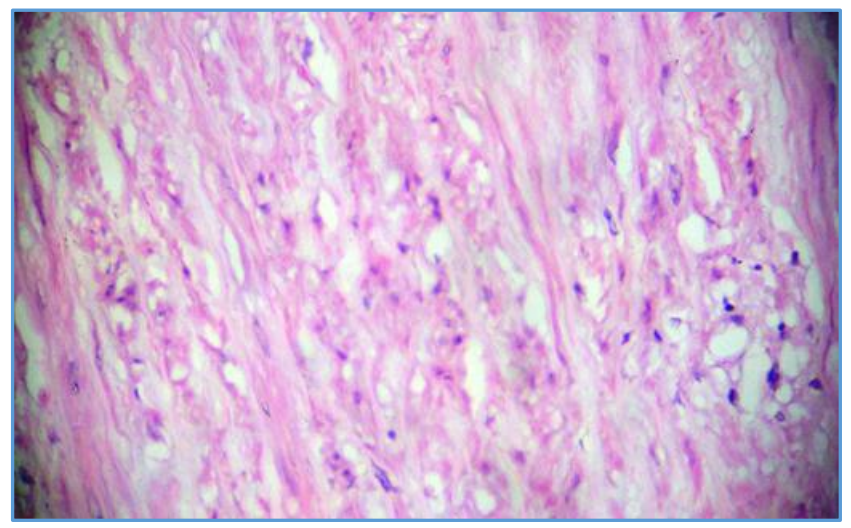

Figure 3. Tunica Media of Ascending Aorta of 78-Year-Old Male showing Atrophy of Smooth Muscle Cells (H\&E $\& 400)$

\section{DISCUSSION}

The collagen fibres, smooth muscle cells and elastic fibres in the vessel wall are the primary load bearing components. ${ }^{(8)}$ Tunica media consists almost entirely of concentric circularly arranged, fenestrated elastic lamella between which are found smooth muscle cells and surrounding which are collagen fibres, the whole being imbued with a matrix of ground substance.(9) Vascular smooth muscle cells are anchored to surrounding extracellular proteins via extensions of cytoskeleton, which allow contracting muscle to redistribute tensile force between collagen and elastin and therefore to modulate stiffness in short term.(10) In 1957 Roach and Burton proposed a qualitative model of arterial elasticity, in which it was proposed that at low arterial pressures the tension is borne by elastin, while the much stiffer collagen remain folded.(11) As pressure and stretch increases, gradual unfolding of collagen fibres take on an increasing fraction of the tension and the vessel becomes progressively stiffer, thus preventing over distension at high pressures.(10)

The thickness of tunica media with respect to full wall thickness was highest in 4 th decade, which was $72.4+2.2 \%$. Thereafter, a fall in mean percentage thickness was observed. In studies conducted by Sankar Dayal Gupta et al,(1) it was noticed that in case of abdominal aorta they measured the thickness of tunica media across different age groups and found that thickness increased until the 6th decade and thereafter it decreased. 
In foetus of last trimester, children of 1st and 2nd decade elastic fibres were long, parallel and closely packed with circularly arranged smooth muscle cells running between elastic lamina. Increase in number of lamellae was also noticed with each decade. From 3rd decade of life, fragmentation of elastic fibres started and higher grades of fragmentation occurred from $50^{\text {th }}$ year of life.

Lakatta EG(12) showed that elastic fibres in tunica media of aorta of infants were having thick elastic membranes. Bloom and Fawcett(13) showed that number and thickness of elastic membranes in media of aorta increased in early childhood. Beyond 6th decade, higher grades of elastic fragmentations were observed. L. S. Foster(14) studied the changes occurring in elastic fibres of aorta with advancing age and found that degenerative changes occurred in elastic fibres of aorta from about fiftieth year up to the end of life. Donalt Tames and Edward have also shown that elastic laminae become thinned and show much fragmentation by the age of 45 years with occasional clumping.(1)

L. S. Foster(14) also showed that with advancing age, the quantity of muscle tissue is greatly diminished and muscle bundles frequently showed fatty changes. Nuclei are scattered and poorly stained. In the present study also, there was a significant decrease in smooth muscle cells with advancing age and there was a change in their orientation also.

Cattell(15) reported that there was an increase in collagen concentration in the wall of ascending aorta within the age group of 14 - 90 years, while the amount of collagen decreased. Andreotti et al reported an increase in collagen content with ageing.(16) Bruel et al reported that the total amount of collagen was not changed, but increment in aortic diameter resulted in less collagen per $\mathrm{mm} 2$ of the aortic wall.(17) In the present study, a quantitative measurement of collagen could not be made; however, with advancing age as the elastic fibres fragmented collagen was found to occupy the space between fragmented elastic fibres.

\section{CONCLUSION}

Thus, it was interpreted from the study that in ascending aorta from $6^{\text {th }}$ decade of life, thickness of tunica media was found to decrease in relation to the full wall thickness. Grade 3 and Grade 4 elastic fragmentation was noticed after 50 years. Maximum number of smooth muscles were observed in foetal group. Atrophy of smooth muscle cells and changes in its orientation were marked after 50 years. Collagen occupied the space between fragmented elastic fibres. These structural changes occurring in the vessel wall got more pronounced after 50 years. Interestingly, any kind of pharmacological approaches to reverse these changes will surely give way to newer treatment options for essential hypertension and other vascular diseases.

\section{REFERENCES}

1. Gupta SD, Gupta SK, Pal DK, et al. Microscopic study of aorta in relation of different age groups:an observational study. Int J Biol Med Res 2011;2(1):398-403.

2. Franklin SS. Blood pressure and Cardiovascular disease: what remains to be achieved? J Hypertens Suppl 2001;19(3):S3-8.

3. Hajjar I, Kotchen TA. Trends in prevalence, awareness, treatment and control of hypertension in the United States, 1998-2000. J Am Med Assoc 2003;290(2):199-206.

4. Wilkinson B, McEniery CM. Arterial stiffness, endothelial function and novel pharmacological approaches. Clin Exp Pharmaco Physiol 2004;31(11):795-9.

5. McManus JFA, Mowry RW. Staining methods: histologic \& histochemical. New York: Hoeber PB Inc Med Divn of Harper \& Row 1960.

6. Evans WC. Quantitative microscopy. Trease and Evan's pharmacognosy. 14th edn. WB Saunders Co Ltd., 1966:57678.

7. Schlatman TJ, Becker AE. Histologic changes in normal aging aorta: implications for dissecting aortic aneurysm. Am J Cardiol 1977;39(1):13-20.

8. Silver FH, Horvath I, Foran DJ. Viscoelasticity of the vessel wall: the roll of collagen and elastic fibers. Crit Rev Biomed Eng 2001;29(3):279-301.

9. Gray's Anatomy. The anatomical basis of clinical practice. $40^{\text {th }}$ edn. Churchill Livingstone: Elsevier 2008:983-4,1358.

10. Greenwald SE. Ageing of the conduit arteries. Journal of Pathology 2007;211(2):157-72.

11. Roach MR, Burton AC. The reason for the shape of the distensibility curves of arteries. Can J Biochem Physiol 1957;35(8):681-90.

12. Lakatta EG. Arterial and cardiac aging major share holders in cardiovascular disease enterprises. Part III: cellular and molecular clues to heart and arterial aging. Circulation 2003;107(3):490-7.

13. Fawcett DW. Bloom and Fawcett: A textbook of histology. $12^{\text {th }}$ edn. New York: Chapman and Hall 2001:359-582.

14. Foster LS. Changes occurring in the elastic fibres of the aorta with advancing age. Journal of Medical Research 1909;21(2):297-311.

15. Cattell MA, Anderson JC, Hasleton PS. Age related changes in amounts and concentration of collagen and elastin in normotensive human thoracic aorta. Clin Chim Acta 1996;245(1):73-84.

16. Andreotti L, Busotti A, Cammelli D, et al. Aortic connective tissue in ageing-a biochemical study. Angiology 1985;36:872-9.

17. Bruel A, Oxlund H. Changes in biochemical properties, composition of collagen and elastin, and advanced glycation end products of the rat aorta in relation to age. Atherosclerosis 1996;127(2):155-65. 